\title{
O ENSINO DE GEOGRAFIA NO CURSO DE PEDAGOGIA: AS POSSIBILIDADES, OS LIMITES E OS DESAFIOS NO PROCESSO DA FORMAÇÃO DOCENTE
}

\author{
Israel David de Oliveira Frois ${ }^{1}$
}

\begin{abstract}
1 Centro Universitário do Espírito Santo (UNESC), Licenciado em Geografia pela Universidade Federal do Espírito Santo, mestre em Ensino em Humanidades pelo Instituto Federal do Espírito Santo. Professor do curso de Pedagogia no Centro Universitário do Espírito Santo (UNESC - Serra/ES). Pesquisador vinculado ao Grupo de Estudos e Pesquisa sobre Educação na Cidade e Humanidades (GEPECH-IFES). E-mail; israelfrois@gmail.com; Orcid: http://orcid.org/0000-0003-3529-6297
\end{abstract}

Artigo recebido em 15/12/2020 e aceito em 28/04/2021

\begin{abstract}
RESUMO
Este artigo tem como objetivo evidenciar questões e reflexões levantadas no desenvolvimento da disciplina de "Fundamentos Teóricos e Metodológicos do Ensino de Geografia", ministrada entre os anos de 2018 a 2020 em uma Instituição de Ensino Superior (IES) privada do município de Serra-ES. Colocamos em relevo a importância da alfabetização geográfica para a práxis docente nos anos iniciais do ensino fundamental, especialmente no domínio teórico-conceitual na formação dos professores pedagogos para o processo de mediação do desenvolvimento do olhar geográfico sobre a realidade. Apontamos os caminhos percorridos no âmbito da disciplina referida, assim como os seus desafios, os seus limites e as suas possibilidades. Para tal, debruçamo-nos na metodologia qualitativa mediante ao levantamento, leitura e análise bibliográfica e, assim, dialogamos com autores que tratam da especificidade do ensino da Geografia Crítica, além de analisar os resultados de um questionário semiestruturado aplicado aos discentes do curso de Pedagogia matriculados na disciplina supracitada. Nesse trabalho deduzimos que a oferta de uma única disciplina relacionada à Geografia durante a licenciatura em Pedagogia pode ser potencializada pelo planejamento docente e pela articulação entre a pedagogia histórico-crítica e Geografia Crítica. Entretanto, faz-se necessário considerar diversos fatores contraditórios que colocam limites e desafios no processo de formação integral dos pedagogos no âmbito do ensino de Geografia.
\end{abstract}

Palavras-chave: Alfabetização Geográfica; Geografia Crítica; Pedagogia Histórico-Crítica. 


\title{
GEOGRAPHY TEACHING IN THE PEDAGOGY COURSE: THE POSSIBILITIES, LIMITS AND CHALLENGES IN THE PROCESS OF TEACHING TRAINING
}

\begin{abstract}
This article aims at highlighting issues and reflections raised in the development of the discipline "Theoretical and Methodological Foundations of Geography Teaching", taught between the years 2018 and 2020 at a private Higher Education Institution (IES) in the municipality of Serra-ES. We emphasize the importance of geographic literacy for teaching praxis in the early years of elementary school, especially in the theoretical-conceptual domain in the training of pedagogical teachers for the process of mediation of the development of the geographical look at reality. We point out the paths taken in the scope of that discipline, as well as its challenges, limits and possibilities. To this end, we focus on the qualitative methodology through a survey, reading and bibliographic analysis and, thus, we dialogue with authors who deal with the specificity of the teaching of Critical Geography, in addition to analyzing the results of a semi-structured questionnaire applied to students enrolled at the pedagogy course who took the aforementioned discipline. In this paper, we deduce that the offer of a single discipline related to geography during the Pedagogy course can be strengthened by teaching planning and by the articulation between historical-critical pedagogy and critical geography. However, it is necessary to consider several contradictory factors that place limits and challenges in the process of integral training of educators within the scope of geography teaching.
\end{abstract}

Keywords: Geographic Literacy; Geography teaching; Critical Geography. Historical-Critical Pedagogy.

\section{ENSEÑANZA DE GEOGRAFÍA EM EL CURSO DE PEDAGOGÍA: POSIBILIDADES, LÍMITES Y RETOS EM EL PROCESO DE ENSEÑANZA DE FORMACIÓN}

\begin{abstract}
RESUMEN
Este artículo tiene como objetivo resaltar cuestiones y reflexiones planteadas en el desarrollo de la disciplina "Fundamentos Teóricos y Metodológicos de la Enseñanza de la Geografía", impartida entre los años 2018 a 2020 en una Institución de Educación Superior (IES) privada en el municipio de SerraES. . Destacamos la importancia de la alfabetización geográfica para la enseñanza de la praxis en los primeros años de la escuela primaria, especialmente en el dominio teórico-conceptual en la formación de docentes pedagógicos para el proceso de mediación del desarrollo de la visión geográfica de la realidad. Señalamos los caminos tomados en el ámbito de la mencionada disciplina, así como sus retos, límites y posibilidades. Para ello, nos centramos en la metodología cualitativa a través de la encuesta, la lectura y el análisis bibliográfico y, así, dialogamos con autores que abordan la especificidad de la enseñanza de la Geografía Crítica, además de analizar los resultados de un cuestionario semiestructurado aplicado a los alumnos del curso de pedagogía. inscrito en la disciplina antes mencionada. En este trabajo deducimos que la oferta de una sola disciplina relacionada con la geografía durante la licenciatura en pedagogía se puede potenciar mediante la planificación docente y mediante la articulación entre pedagogía histórico-crítica y geografía crítica. Sin embargo, es necesario considerar varios factores contradictorios que ponen límites y desafíos en el proceso de formación integral de los pedagogos en el campo de la enseñanza de la geografía.
\end{abstract}

Palabras clave: Alfabetización geográfica; Enseñanza de la geografia; Geografía crítica. Pedagogía histórico-crítica. 


\section{INTRODUÇÃO}

No final do século XX, sob forte influência do ideário neoliberal, observou-se o desenvolvimento de uma série de reformas das políticas educacionais de caráter neoliberalizante, com destaque para os governos de Fernando Henrique Cardoso (1995-2002) (FERREIRA; TARTAGLIA, 2020), cujo objetivo estava intrinsicamente ligado às demandas de expansão do capital, tanto geograficamente, quanto em novos "nichos" (HARVEY, 2005). Tais reformas educacionais estiveram em sintonia uníssona com as propositivas formuladas pelos organismos internacionais, como a Organização das Nações Unidas para a Educação, a Ciência e a Cultura (UNESCO), o Banco Mundial, o Banco Interamericano de Desenvolvimento (BID) e a Organização Mundial do Comércio (OMC).

No bojo desse cenário, surgem muitas instituições de ensino superior (IES) privadas e, a reboque, as licenciaturas de Pedagogia. O enlace com o capital prosseguiu nos governos subsequentes de Luís Inácio Lula da Silva (2003-2010) e de Dilma Rousseff (2011-2016), com o aprofundamento das Parcerias Público Privadas (PPP) e com os programas de financiamento e bolsas estudantis (FERREIRA; TARTAGLIA, 2020), assim como no alargamento das possibilidades do ensino à distância $(\mathrm{EaD})$.

Dessa forma, sob o incentivo do Estado como articulador do capital, foi notório o aumento da oferta de cursos de graduação nos últimos anos, a despeito de sua qualidade nas formações iniciais, sobretudo das licenciaturas ofertadas em muitas IES que visam, exclusivamente, o aumento dos rendimentos via captação de clientela e aporte de recursos financeiros do Estado. Assim, o número de estudantes universitários de Pedagogia aumentou consideravelmente.

Cabe destacar, conforme aponta Saviani (2009) em análise sobre a formação de professores no Brasil, que a Lei de Diretrizes e Bases (BRASIL, 1996) sinalizou para uma política educacional tendenciada a fazer o nivelamento "por baixo". O autor enfatiza ainda que “os institutos superiores de educação emergem como instituições de nível superior de segunda categoria, provendo uma formação mais aligeirada, mais barata, por meio de cursos de curta duração" (SAVIANI, 2008b, p. 218).

Ao analisar os dados do relatório do Exame Nacional de Desempenho de Estudantes (ENADE) de 2017, Ferreira e Tartaglia (2020), em trabalho intitulado "Perfil e formação dos 
estudantes de pedagogia no Brasil: um relato de experiência desde as IES privadas", apontam que

[...] o perfil geral do/a estudante do curso de Pedagogia é de uma população que tem origem na classe economicamente desfavorecida, geralmente com pouco ou nenhum acesso aos bens culturais produzidos pela humanidade e, provavelmente, com baixa condição de lazer. Ainda consideramos que o perfil do curso do/a estudante de Pedagogia é de classe desfavorecida economicamente, cuja família também possui baixa escolarização e sem acesso aos bens culturais, torna mais conveniente a essas instituições um currículo que seja mais fácil de ser cumprido e não que forme professores com consciência de classe (FERREIRA; TARTARGLIA, 2020, p. 29).

Então, se por um lado observamos que o acesso ao curso de pedagogia é uma alternativa na busca pela melhoria das condições de vida dos indivíduos que, mesmo diante de tantas barreiras sociais, conseguem acessar as IES, por outro lado, a condição de classe destes sujeitos impõe muitos desafios e dificuldades que podem interferir no processo de formação dos pedagogos e das pedagogas.

Considerando todas estas questões estruturais e conjunturais brevemente indicadas, essa é a situação em que o curso de Licenciatura em pedagogia se insere atualmente e, dentro do curso, a disciplina de Ensino de Geografia, que é ofertada com várias nomenclaturas diferentes pelas IES do Brasil, tais como: Metodologias de Ensino de Geografia; Fundamentos Teóricos e Metodológicos do Ensino de Geografia; Geografia - conteúdo e metodologia; Metodologias das Ciências Humanas: Geografia; Educação em Geografia; Escola, Conhecimento e Metodologias: História e Geografia, dentre outras. Ressaltamos que, geralmente, é ofertada uma única disciplina no âmbito da Geografia ao longo de toda a licenciatura para tratar, mais objetivamente, de aspectos metodológicos. Portanto, há dificuldades evidentes nas discussões de fundo teórico-conceitual.

Sabemos que o ensino de Geografia nos primeiros anos do fundamental envolve muitos desafios, principalmente quando consideramos as especificidades do conhecimento geográfico e o momento de grande importância da educação básica no processo de alfabetização integral dos sujeitos. Dentre os desafios e dificuldades, destacam-se: as deficiências no ensino básico no histórico de formação do estudante de Pedagogia; as formações iniciais aceleradas e de pouca profundidade e a oferta de apenas uma disciplina vinculada à especificidade do ensino de Geografia. 
Dessa forma, surgem algumas questões que guiaram as nossas reflexões, tais como: “será que a licenciatura de Pedagogia, em específico a disciplina de 'Fundamentos Teóricos e Metodológicos do Ensino de Geografia' é suficiente para mediar o processo de alfabetização geográfica dos pedagogos e pedagogas em formação?" e "os estudantes do curso de licenciatura em pedagogia conseguirão atuar de forma a mediar a construção do raciocínio e do olhar geográfico dos estudantes?”

Nesse sentido, buscamos nos aproximar de respostas para tais questões a partir do diálogo com autores do campo do ensino da Geografia. Em destaque, os trabalhos sobre: formação de professores e ensino de Geografia (CASTELLAR, 1999; 2005; BRAGA, 2007; CALLAI, 2011); ensino de Geografia e educação infantil (STRAFORINI,2004; CAMACHO, 2011; SILVA; SILVA, 2018); alfabetização geográfica e metodologia de ensino de Geografia (CASTROGIOVANNI; GOULART, 1990; CAVALCANTI，1998; 2010; GONÇALVES; PINTO, 2015; FANTIN; TAUSCHEK; NEVES, 2013); e ensino de Geografia e pedagogia histórico-crítica (COUTO, 2009; TEIXEIRA, 2015). A seleção desses autores foi realizada mediante a busca e levantamento em periódicos do campo do ensino de Geografia. A partir da leitura prévia foram escolhidos os trabalhos em que há identificação com o fundo teórico-crítico que embasou a nossa práxis docente na disciplina "Fundamentos Teóricos e Metodológicos do Ensino de Geografia”.

O nosso foco especial nesse trabalho é levantar reflexões e diálogos sobre as possibilidades, os limites e os desafios do processo de alfabetização geográfica na formação inicial de pedagogia. Assim, esta pesquisa apresenta o caráter metodológico qualitativo mediante a pesquisa, leitura e análise bibliográfica dos autores supracitados. Evidenciamos, ainda, algumas experiências vivenciadas na disciplina de "Fundamentos Teóricos e Metodológicos do Ensino de Geografia”, ministrada entre os anos de 2018 e 2020 em uma Instituição de Ensino Superior (IES) privada no município de Serra, Espírito Santo. Nesse caso, aplicamos um questionário semiestruturado aos cursistas da disciplina em destaque que possibilitou a escuta, o diálogo e reflexões sobre a importância do ensino de Geografia e os seus limites e desafios. Entendemos que esse caminho percorrido consiste em oportunizar aos estudantes exporem suas apreensões sobre a disciplina ofertada, bem como, evidentemente, nos proporciona um suporte que demonstra a necessidade das nossas análises e a validade dos questionamentos. 
Em nossa atuação estruturamos a escrita, inicialmente, apresentando as bases conceituais sobre o processo de alfabetização geográfica, pois entendemos como é indispensável para a práxis docente na educação infantil e nos anos iniciais do ensino fundamental. Em seguida, colocamos em destaque questões relacionadas à importância do desenvolvimento do olhar geográfico para o espaço social (SANTOS, 2008) no processo educativo. Por fim, apontamos os caminhos percorridos no desenvolvimento da disciplina "Fundamentos Teóricos e Metodológicos do Ensino de Geografia” em diálogo com referências do campo do ensino de Geografia.

\section{A GEOGRAFIA ESCOLAR E A ALFABETIZAÇÃo GEOGRÁFICA}

Desde o desenvolvimento da Geografia como ciência moderna, percebe-se a instrumentalização desta disciplina das ciências humanas para fins de dominação e manutenção de poder (LACOSTE, 1988), inclusive na construção ideológica de narrativas favoráveis aos interesses territoriais e, intrinsicamente, econômicos. Passando pela Geografia Alemã de Ratzel e a Geografia Francesa de Vidal de La Blache, ambas desenvolvidas no contexto imperialista do século XIX, até o século XX, com a ascensão da Geografia Teorético-Quantitativa da escola anglo-saxônica, no contexto do Pós Grandes Guerras (MOREIRA, 1998), nota-se o desenvolvimento de escolas do pensamento geográfico comprometidas com o modus operandi da dinâmica capitalista.

Nesses casos, a Geografia escolar servia como forma de dominação ideológica, no sentido de instrumentalizar o espaço e os conteúdos escolares para a reprodução da ordem sistemática. Isso não quer dizer que atualmente a escola não tem cumprido, em grande medida, essa função ideológica (SAVIANI, 2001), mas que, em um primeiro momento, as concepções geográficas contra-hegemônicas foram soterradas, isto é, subalternizadas e excluídas do debate acadêmico hegemônico e, consequentemente, impedidas de chegarem até as salas de aula.

Apenas no contexto do Pós $2^{\mathrm{a}}$ Guerra e do mundo bipolarizado é que observamos a emergência de uma Geografia crítica à ordem sistemática, a Geografia Crítica ou Radical. Para Vesentini

Trata-se de uma Geografia que concebe o espaço geográfico como espaço social, construído, pleno de lutas e conflitos sociais [...]. Critica a Geografia Moderna no sentido dialético do termo crítica: superação como subsunção, e compreensão do papel histórico daquilo que é criticado. Essa Geografia Radical ou crítica coloca-se como ciência social, mas estuda também a natureza enquanto recurso apropriado pelos 
homens e enquanto uma dimensão da história, da política. No ensino, ela se preocupa com o senso crítico do educando e não em "arrolar os fatos" para que ele memorize. Suas fontes de inspiração vão desde o marxismo (especialmente o próprio Marx), até o anarquismo (onde se recupera autores como Éliseé Reclus e Piotr Kropotkin) [...] (VESENTINI, 2012, p. 36).

É relevante salientar que a Geografia Crítica ou Radical foi a primeira escola de pensamento geográfico a romper com ditames do capital e, ao contrário das escolas predecessoras, colocou-se na posição de enfrentamento diante das contradições objetivadas pelo sistema capitalista. Nesse aspecto, todas as características relacionadas à neutralidade da pesquisa geográfica, do pesquisador e do professor, bem como às abordagens meramente descritivas ou apenas relacionadas à matematização do espaço, foram levantadas em debate $\mathrm{e}$ contrapostas pela corrente Crítica.

Cabe ressalvar que a Geografia acadêmica e a Geografia escolar, embora tenham as suas especificidades e suas diferenças no que diz respeito aos objetivos, funções e finalidades, mutualmente se encontram, se envolvem e se influenciam (CAVALCANTI, 2010). Segundo Callai

[...] a Geografia escolar, é resultado da seleção de que conteúdos trabalhar a partir daquilo que é o especifico da ciência geográfica. Mas, que se constitui a partir de um conjunto de fatores que passam pelo estabelecimento de um conhecimento sustentado no trabalho a partir de elementos significativos. Estes permitem estabelecer e consolidar as raízes daquilo que se convenciona como Geografia escolar (CALLAI, 2011, p. 3).

Evidencia-se que tais elementos significativos se dão a partir das relações entre os professores e o trabalho docente, as formações iniciais e continuadas, vivências escolares e cidadã, dentre outros aspectos contextuais e escolares (CALLAI, 2011).

Não obstante ainda possamos observar a remanescência do pensamento tradicional nas práticas escolares, é notório também que o quadro teórico-conceitual da Geografia Crítica desde o último quarto do século $\mathrm{XX}$ entrou na escola, inicialmente com pouca clareza teórica (FANTIN; TAUSCHEK; NEVES, 2013) e, ainda hoje, com certas dificuldades de ser trabalhada de forma coerente. Inferimos, então, a necessidade de conduzir a formação e o trabalho docente mediante a uma corrente pedagógica coerente com o caráter da Geografia Crítica. Nesse caminho, entendemos que a pedagogia histórico-crítica (SAVIANI, 2008a) se articula coerentemente com tal perspectiva geográfica (COUTO, 2009; TEIXEIRA, 2015), pois ambas estão fundadas na perspectiva marxista, isto é, no materialismo histórico e dialético. 
Em estudo desenvolvido por Gonçalves e Pinto (2015), foi realizado um levantamento histórico e bibliográfico do movimento de alfabetização geográfica no Brasil. Nesse estudo são apresentadas as perspectivas de entendimento da alfabetização geográfica desde o período colonial com a educação jesuítica, passando pela institucionalização da educação pública e as sequenciais reformas educacionais. Gonçalves e Pinto (2015) salientam que apenas no final do século XX, no período de emergência da Geografia Crítica ou Radical, há discussões profícuas sobre o processo de alfabetização geográfica em contraponto à abordagem tradicional descritiva e mnemônica dos elementos do espaço.

Nesse cenário, observou-se uma série de ressignificações de conceitos e mudanças de paradigmas no pensamento geográfico que suscitaram a necessidade e a urgência de redefinir os objetivos, as metodologias de ensino-aprendizagem e as abordagens dadas aos conteúdos. Torna-se, então, imperioso dar atenção ao processo de formação docente, a fim de possibilitar o domínio do instrumental teórico geográfico, por parte do professor, sobretudo dos pedagogos e pedagogas atuantes nos anos iniciais do ensino fundamental. Em primeiro lugar, afirmamos que é imprescindível a compreensão do objetivo maior da Geografia escolar nessa etapa inicial, qual seja: mediar o processo de alfabetização geográfica, para que os estudantes possam fazer a leitura do espaço, isto é, desenvolver o raciocínio e o olhar geográfico (FANTIN; TAUSCHEK; NEVES, 2013). Nesse prisma de compreensão é possível estabelecer um trabalho pedagógico organizado e planejado para atender a esse objetivo.

A partir do entendimento de que nos anos iniciais do ensino fundamental a preocupação central do ensino de Geografia é "[...] a construção da noção espaço-temporal” (FANTIN; TAUSCHEK; NEVES, 2013, p.75), compreendemos também que é imprescindível, no processo dessa construção, que a práxis docente ocorra considerando dois eixos: a formação de conceitos científicos e geográficos e a alfabetização cartográfica. Ambos, além de serem indispensáveis no processo de formação da noção espaço-temporal, estão imbricados ao desenvolvimento da alfabetização geográfica (FANTIN; TAUSCHEK; NEVES, 2013).

Afirmamos que a Geografia como ciência integrante das ciências humanas tem a suas especificidades e, dentre elas, sua linguagem geográfica se destaca. Envolve, dessa forma, o conjunto de conceitos, representações e vocabulário específicos. Assim, na Geografia escolar é indispensável a mediação para a constituição de um entendimento das categorias e linguagem, pois da mesma forma que é necessário o processo de alfabetização da língua portuguesa, como 
forma de se estabelecer a relação do estudante com o mundo a partir das palavras e da semântica, faz-se necessário a alfabetização no que concerne a linguagem geográfica como instrumental para a leitura do espaço social, isto é, do espaço geográfico, objeto de estudo da Geografia.

De acordo com Fantin, Tauschek e Neves (2013), o processo de alfabetização geográfica propicia ao estudante a leitura do espaço geográfico promovendo a compreensão da realidade por intermédio do estudo da sua fisicidade como uma construção histórica e social (FANTIN; TAUSCHEK; NEVES,2013). Tal processo, possibilita um olhar instrumentalizado para a realidade, muito mais profundo do que a simples descrição e mnemonização de continentes, países, estados e cidades. Assim, a alfabetização geográfica tem o caráter capaz de mediar o processo de conscientização e formação humana, possibilitar a compreensão da dimensão espaço-temporal e suas escalas, além de provocar o desvelamento da aparência da realidade, isto é, permite um olhar mediado para o espaço possibilitando a leitura do mundo.

Cavalcanti indica que

\begin{abstract}
A leitura do mundo do ponto de vista de sua espacialidade demanda a apropriação, pelos alunos, de um conjunto de instrumentos conceituais de interpretação e de questionamento da realidade socioespacial [...]. Esses conceitos - lugar, paisagem, região, natureza, sociedade, território - são considerados como conceitos fundamentais para o raciocínio espacial [...] (CAVALCANTI, 1998, p. 25-26).
\end{abstract}

Portanto, ao mediar o processo de apropriação dos instrumentos conceituais observamos o desenvolvimento do olhar e do raciocínio geográficos dando possibilidades de reflexão, interpretação e maior compreensão da realidade. Evidenciamos que tal desenvolvimento mediado pelas categorias e pela linguagem geográfica torna possível um olhar instrumentalizado para o espalho geográfico, que propicia a interpretação da realidade. Girotto (2015, p. 82), contribui ao destacar "a necessidade que o estudante, ao se apropriar de conceitos, conteúdos e linguagens e ferramentas da Geografia, possa construir um raciocínio geográfico sobre o mundo em que vive". Castrogiovanni e Goulart (1990, n.p.) salientam que "o estudo de Geografia deve desenvolver noções de espacialidade materializadas e sensitivas (relações), desenvolver a formação da consciência territorial, tão comumente adormecida no Brasil [...]”. Para tal desenvolvimento, as noções cartográficas são de suma importância, haja vista que entendemos o espaço como constructo socialmente produzido ao longo da história e, nesse sentido, a cartografia tem uma função determinada e tem como finalidade facilitar a leitura e a 
compreensão do espaço (CASTROGIOVANNI; GOULART, 1990). Entendemos que a representação gráfica do espaço é instrumento para a construção do raciocínio geográfico e que a apreensão da representação espacial é consequência de um processo delongado e que está relacionado com o desenvolvimento da noção de profundidade, lateralidade, anterioridade, noção topológica, euclidiana e projetiva (FANTIN; TAUSCHEK; NEVES, 2013).

Percebem-se, então, a importância e a centralidade da questão espacial no âmbito da Geografia. Em seguida, apresentamos alguns apontamentos e reflexões sobre o olhar geográfico para o espaço a partir da perspectiva da Geografia Crítica.

\section{APARÊNCIA E ESSÊnCIA: O OLHAR GEOGRÁfiCO PARA O ESPAÇO E A GEOGRAFIA ESCOLAR}

Para a Geografia o espaço geográfico tem um caráter central. Há de se considerar a dimensão temporal deste espaço social (SANTOS, 2008), estabelecendo, assim, uma indissociabilidade da relação espacialidade-temporalidade, pois o espaço sempre estará associado aos tempos pelos quais passou. A espacialidade, de acordo com Ramos, pode ser entendida como "forma de organização espacial datadas de outros momentos", pensado, então, “[...] como processo histórico [...] num constante movimento dialético" (1982, p. 68). Observase, então, uma longa sobreposição espaço-temporal. Por exemplo, os solos cultiváveis de hoje foram gerados por processos geológicos de bilhões a milhões de anos. Antes de serem solos, foram rochas; antes de rochas, magma; antes de magma, poeira cósmica. As técnicas mais sofisticadas da agricultura objetivadas no espaço agrícola no século XXI foram construídas socialmente ao longo do tempo, desde as primeiras transformações humanas realizadas pelo metabolismo social, ou seja, o trabalho humano (FOSTER, 2014). Olhar para um espaço agrícola pode nos provocar idas e vindas no tempo, considerando este mesmo espaço, antes e depois da presença do ser humano.

O geólogo escocês James Hutton, pai da geologia moderna dizia que "o presente é a chave do passado" (TEIXEIRA et al., 2007, p. 315). A partir desta ilustração, podemos relacionar com o movimento dialético, no qual a realidade em que vivemos pode ser apreendida para a compreensão do passado e dos processos de outrora, bem como os processos do passado podem ser apreendidos para a compreensão da realidade em construção constante (devir). Para a Geografia, portanto, o olhar mais amplo para o espaço geográfico predispõe dessa sintonia espaço-temporal. 
Para além de um olhar mecanicista biológico, Marx utilizando uma analogia para explicar a sociedade burguesa, chegou à conclusão de que "[...] a anatomia do homem é a chave da anatomia do macaco" (MARX, 2004, p. 120), isto é, o ser humano, fruto de um processo natural, social e histórico, como ser mais desenvolvido, carrega consigo as marcas deste processo fundado no devir histórico. Nesse sentido, podemos também compreender a anatomia do espaço, pois a forma materializada ou as rugosidades da realidade espacializada são as formas mais avançadas que congregam em si as marcas que podem gerar a compreensão dos processos e movimentos de produção da espacialidade. Observa-se que o uso da expressão tem origem na Física Clássica para expressar as marcas acumuladas nos equipamentos em função de movimentos anteriores. Dessa forma, Milton Santos (2002) utilizou o termo rugosidade como analogia para compreender tempos de outrora materializados nas formas do presente.

Ao discutir sobre produção e espaço Santos (2008) afirma que,

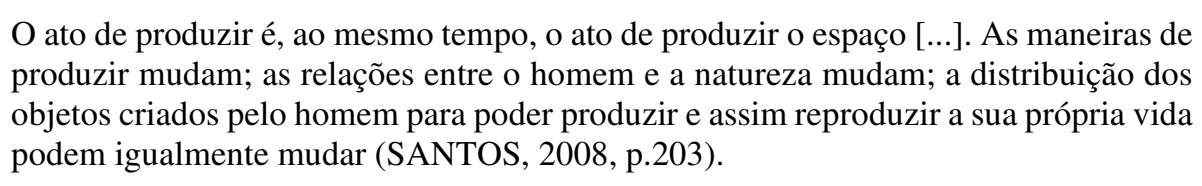

Dessa forma, compreende-se o “[...] espaço como conjunto contraditório, formado por uma configuração territorial e por relações de produção, relações sociais; e, finalmente, [...] o espaço formado por um sistema de objetos e um sistema de ações" (SANTOS, 1994, p. 110). Além disso, o conceito de espaço "[...] reúne o mental e o cultural, o social e o histórico" (LEFEBVRE, 2006, p. 9), do mesmo modo, “[...] não pode, portanto, ser isolado e permanecer estático. Ele se dialetiza: produto-produtor, suporte de relações econômicas e sociais" (LEFEBVRE, 2006, p. 7). Depreendem-se, então, a importância e a necessidade de buscar desvelar esses processos sociais e históricos de produção das condições objetivas e subjetivas da existência humana e, ao mesmo tempo, da espacialidade produzida, resultante do intercâmbio do homem com a natureza ao longo do tempo.

Por isso, os movimentos realizados para a percepção da realidade precisam considerar a totalidade que este real congrega. Assim, todo e qualquer entendimento, necessariamente, precisa ir além de um olhar imediato, rápido e superficial. Faz-se necessário extrapolar a aparência da realidade, do espaço geográfico. Lembramos que, para Santos, a "[...] paisagem é um conjunto heterogêneo de formas naturais e artificiais; é formada por frações de ambas, seja quanto ao tamanho, volume, cor, utilidade, ou por qualquer outro critério. A paisagem é sempre 
heterogênea" (SANTOS, 1996, p. 65). Sob este aspecto, sendo a paisagem a fração do espaço que está aos nossos olhos, ou seja, a unidade visível do espaço geográfico, a sua análise está em um patamar primário de percepções. Assim, da mesma forma que o movimento que o Sol aparenta fazer de leste para oeste, na verdade, trata-se do movimento de rotação da Terra no sentido oposto (Oeste para Leste), várias outras percepções imediatas do espaço geográfico podem esconder a realidade.

Entende-se que a aparência não revela a totalidade da realidade, por isso, é preciso problematizar o que se vê, analisar e investigar cientificamente para buscarmos a aproximação da essência, haja vista que a paisagem pode revelar alguns aspectos da realidade, porém, pode esconder tantos outros. A partir daí, busca-se desvelar a aparência imediata, problematizando e lançando o uso de instrumentos teóricos-empíricos para nos aproximarmos da essência da realidade concreta (KOSIK, 2010).

Dessa maneira, compreendemos o papel fundante da educação, em especial da educação e da Geografia escolar, na mediação da alfabetização geográfica, no desenvolvimento de um olhar para além do senso comum, além dos apriorismos e preconceitos com o intuito de "[...] compreender as determinações que se ocultam sob as aparências dos fenômenos que se manifestam empiricamente à nossa percepção" (SAVIANI, 2015, p. 36).

Nessa perspectiva, a partir da pedagogia histórico-crítica entendemos educação como mediação no seio da prática social global e como tal "cabe possibilitar que as novas gerações incorporem os elementos herdados de modo que se tornem agentes ativos no processo de desenvolvimento e transformação das relações sociais" (SAVIANI, 2008, p. 143). A educação, sobretudo a escolar, é fundamental no processo de humanização dos sujeitos. Tal humanização é realizada na medida em que se promove a apropriação dos elementos culturais e conteúdos sistematizados produzidos historicamente pela humanidade. Entretanto, sabemos que ao longo da história esses conteúdos sistematizados foram negados aos grupos e classes subalternizados e, por isso, concordamos com Teixeira (2015, p. 195) ao dizer que a pedagogia histórico-crítica muito contribui na "superação do esvaziamento dos conhecimentos no ensino de Geografia que se pratica no âmbito da escola pública”.

Acreditamos na potência da Geografia escolar sustentada pela perspectiva teórica da Geografia crítica e da pedagogia histórico-crítica para o processo de aproximação da apreensão da realidade objetivada no espaço geográfico. Por isso, constatamos a elevada relevância do 
trabalho educativo nos primeiros anos da vida estudantil dos sujeitos, pois é neste momento em que o processo de alfabetização deveria ser iniciado.

Entretanto, notamos muitas dificuldades e desafios relacionados à formação dos pedagogos e pedagogas que lecionam para este público-alvo da educação infantil e dos anos iniciais do ensino fundamental. Em seguida, apresentamos a estrutura da disciplina "Fundamentos Teóricos e Metodológicos do Ensino de Geografia", bem como as possibilidades, os desafios e dificuldades enfrentadas ao longo do período de docência da referida disciplina. Por fim, evidenciamos os resultados de um questionário aplicado para os discentes da disciplina em destaque e apontamos alguns questionamentos e reflexões finais.

\section{A FORMAÇÃO EM GEOGRAFIA NA LICENCIATURA DE PEDAGOGIA: UMA DISCIPLINA, MUITOS DESAFIOS}

Como forma de organizar as nossas reflexões, resgatamos as questões que foram apontadas inicialmente, quais sejam: será que a licenciatura de Pedagogia, em específico a disciplina de "Fundamentos Teóricos e Metodológicos do Ensino de Geografia" é suficiente para mediar o processo de alfabetização geográfica dos pedagogos e pedagogas em formação? Os estudantes do curso de licenciatura em Pedagogia conseguirão atuar de forma a mediar o desenvolvimento do raciocínio e do olhar geográfico dos estudantes? Visando nos aproximarmos de respostas para estas questões, estabelecemos diálogos com autores da área de ensino de Geografia. Tais autores subsidiaram o processo de análise das experiências vivenciadas na docência superior em uma IES privada, ao longo dos anos de 2018 a 2020, pelo autor deste trabalho.

Assim como na maioria das licenciaturas de Pedagogia, na IES privada analisada é ofertada apenas uma disciplina que aborda especificamente o ensino de Geografia. Tal disciplina é nomeada de "Fundamentos Teóricos e Metodológicos do Ensino de Geografia" e é ofertada no $3^{\circ}$ período do curso, com a carga horária de 48 horas, sendo 24 horas teóricas e 24 horas práticas. No que diz respeito à carga horária, percebe-se, além de um aligeiramento, uma concepção fragmentária da relação teoria e prática (práxis).

Conforme indica a ementa, os conteúdos selecionados são:

- $\quad$ O Brasil e seu contexto geográfico;

- Aspectos: sociais, políticos, econômicos e culturais; 
- Geografia: procedimentos, recursos e instrumentos didáticos para o ensino;

- $\quad$ O ensino de Geografia nos anos iniciais do ensino fundamental.

Podemos observar que embora o nome da disciplina tenha uma referência direta aos fundamentos teóricos, a ementa da disciplina enfatiza os aspectos de contextualização e, principalmente, os aspectos metodológicos de ensino. Ao observarmos os objetivos contidos na ementa fica mais explícita esta relação:

- Perceber os objetos de estudo da Geografia a partir da realidade do alunado, capacitando-o a produzir o próprio conhecimento de acordo com os seus interesses reais;

- Reconhecer a importância da Geografia como instrumento de conscientização das relações sociedade/natureza, num determinado tempo;

- Conduzir a uma metodologia reflexiva sobre as disciplinas de Geografia através de conteúdos críticos, que contribuam efetivamente para a formação da cidadania dos profissionais do magistério até o ensino médio;

- Demonstrar habilidades na confecção e manuseio de materiais didáticos específicos e de estudo.

Infere-se que, ao seguir rigorosamente a ementa, incorre-se o risco de desconsiderar o perfil social e o histórico escolar dos estudantes de Pedagogia no que tange ao acesso à educação básica de qualidade e ao processo de alfabetização geográfica deficitário ao longo de suas vidas escolares. Nota-se, assim, que as discentes e os discentes do curso de Pedagogia na IES analisada seguem o perfil geral dos estudantes das licenciaturas de Pedagogia no Brasil (FERREIRA; TARTAGLIA, 2020), pois: são oriundos da classe menos favorecida e de baixa renda; histórico familiar de baixo acesso à escolaridade, com pouco acesso à bens culturais; predominantemente composto por pessoas do sexo feminino; em sua maioria de idade até os 29 anos; e preponderantemente declarados pretos ou pardos (negros). Nesse prisma, quando a ementa indica um caminho de trabalho que não tem como objetivo a mediação do processo de domínio dos instrumentos teóricos e conceituais necessários ao ato educativo, percebemos os limites não apenas vinculados ao curto período destinado à disciplina, mas também na perspectiva orientadora da formação do professor. Concordamos com Camacho (2011), pois 
transformar o professor das séries/anos iniciais em um pesquisador especialista da área de Geografia, mas que, pelo menos, domine os conceitos básicos da área e que acompanhe os avanços teóricos produzidos na ciência geográfica, juntamente com os avanços na área da educação, para que assim consiga relacionar teoria e prática em sala de aula (CAMACHO, 2011, p. 10).

Sobre esse aspecto relacionado ao enfoque demasiado nas metodologias em detrimento dos instrumentos teórico-conceituais, Braga (2007) aponta que

Essa característica da maioria dos cursos de formação de Pedagogia de não contemplar a aprendizagem dos conteúdos curriculares a serem ensinados nas séries iniciais, mas apenas as suas metodologias, é um dos fatores que contribui para que a discussão não se coloque nos âmbitos universitários. É também, talvez, um dos motivos pelos quais os professores dessas séries nem sempre ensinem esses conteúdos e priorizem a leitura, a escrita e a matemática (BRAGA, 2007, p. 140).

Nesse ponto, encontramos um importante indicativo para as nossas reflexões, visto que, se a abordagem na graduação é centrada nos aspectos metodológicos, há óbvias dificuldades e, em muitos casos, a formação inicial não é suficiente para subsidiar uma práxis potente e mediadora da alfabetização geográfica na educação infantil e nos anos iniciais do fundamental.

A partir deste entendimento e fazendo-nos valer dos dispositivos legais como, por exemplo, o artigo $206^{\circ}$ da Constituição Federal Cidadã de 1988 e o $\operatorname{artigo~} 3^{\circ}$ da Lei n ${ }^{\circ}$ 9.394/96 (Lei de Diretrizes e Base da Educação Nacional) que tratam da liberdade de cátedra, bem como o pluralismo de ideias e concepções pedagógicas, buscamos contemplar os conteúdos apontados pela ementa, porém, adicionamos e aprofundamos as leituras e discussões sobre os conceitos e categorias geográficas a fim de potencializar o processo de alfabetização geográfica dos discentes do curso de Pedagogia.

Destarte, organizamos a disciplina em três blocos, a saber:

1. Aspectos teóricos conceituais: nesse momento as aulas foram planejadas para serem ministradas de forma expositiva-dialogada com o apoio de diversos materiais educativos (música, audiovisual, imagens e fotografias, aplicativos e jogos), pois mesmo o enfoque sendo o teórico, os aspectos metodológicos precisam ter coerência com a proposta adotada servindo de exemplos que serão explicitados no próximo bloco. Assim, destacamos os seguintes pontos: as correntes do pensamento geográfico e as interfaces com a Geografia escolar; desenvolvimento dos conceitos e categorias basilares para o conhecimento geográfico (espaço, espaço social ou 
geográfico, paisagem, lugar, território, natureza e sociedade etc.) e alfabetização cartográfica;

2. Aspectos contextuais e metodológicos: nessa etapa as aulas se alternam entre exposição dialogada, instrumentalização do laboratório de informática e oficinas temáticas e aula de campo. A nossa abordagem destaca: o currículo e o ensino de Geografia; Geografia regional e local; metodologias de ensino coerentes com o ensino da Geografia Crítica; instrumentos didáticos e produtos educativos. Este bloco da disciplina ocorre o processo de inter-relação entre os aspectos teóricos e conceituais desenvolvidos no primeiro momento;

3. Prática docente em ensino de Geografia: na última parte os pedagogos e pedagogas em formação apresentam a culminância do processo de ensino-aprendizagem em Geografia por meio de duas atividades. São elas: planejamento e execução de um plano de aula em coerência com a perspectiva teórica e metodológica da Geografia Crítica, e avaliação de pelo menos dois capítulos de um livro didático de geografia dos anos iniciais do fundamental. Neste momento do processo os pedagogos e pedagogas em formação evidenciam as suas sínteses de todo o percurso da disciplina.

Cabe salientar que os três blocos são conduzidos de forma integrada e dialética e sob a perspectiva da pedagogia histórico-crítica, considerando os saberes implicados na formação docente segundo Saviani (1996), além do entendimento do processo educativo dialético que envolve: a prática social inicial, marcada pelo estabelecimento do diálogo entre professor e estudantes, pois, no processo educativo, deve-se partir da prática social inicial dos educandos, mesmo estes apresentando uma prática social inicialmente sincrética, isto é, desarticulada, pautada no senso comum. O professor, por sua vez, parte de uma prática social inicial sintética, ou seja, articulada, elaborada por estar pautada nos conhecimentos sistematizados; as problematizações, isto é, a identificação dos problemas/questões que precisam ser respondidos ou considerados tendo em vista a prática social. Para tal movimento, o planejamento docente e o diálogo são imprescindíveis; as instrumentalizações teórico-conceituais e práticas necessárias para mediar as resoluções das questões surgidas no seio da prática social; a catarse, ou seja, um movimento de elaboração elevada proporcionando um novo entendimento da prática social, a partir das instrumentalizações teórico-práticas; a prática social final, o novo patamar de 
apreensão da realidade que deve ser o da retomada do processo educativo, a fim de promover a apreensão cada vez mais aproximada da realidade (SAVIANI, 2001; 2008a).

Sabemos das limitações relativa à carga horária da disciplina, além dos imprevistos e eventos acadêmicos incluídos no calendário que geram o necessário dispêndio de tempo. De fato, as 48 horas geram um apressamento das discussões, dificultando, assim, todo este processo supracitado.

Então, para conseguirmos uma avaliação geral do trabalho desenvolvido na disciplina de "Fundamentos Teóricos e Metodológicos do Ensino de Geografia" no período entre 2018a 2020, elaboramos um questionário (Google Formulários) com questões abertas para constatarmos as percepções dos cursistas da disciplina. Salientamos que todos os estudantes que cursaram a disciplina em destaque e que mantém matrícula na IES foram convidados a responderem o questionário. Nesse caso, contamos com a participação de alunos das turmas de 2018/1 (quatro estudantes), 2019/1 (quatro estudantes) e 2020/1 (seis estudantes) contabilizando o total de quatorze estudantes. Por intermédio da leitura rigorosa das respostas selecionamos aquelas que mais subsidiam análises de acordo com a propositiva deste trabalho. Assim, deixamos de apresentar aquelas respostas muito objetivas ou com respostas evasivas e/ou desconexas.

Elaboramos duas questões que englobam desde as apreensões dos discentes quanto aos conteúdos desenvolvidos à percepção sobre a futura ação docente deles, enquanto pedagogos e pedagogas regentes de sala de aula. Dessa maneira, a primeira questão foi: "O desenvolvimento da disciplina 'Fundamentos Teóricos e Metodológicos do Ensino de Geografia' possibilitou a mediação no processo da sua Alfabetização Geográfica? Justifique:”. Nesta questão observamos que $92 \%$ dos discentes responderam que sim. Entretanto, apenas $65 \%$ dos estudantes justificaram a resposta e apenas $8 \%$ responderam não, também sem justificar. Daqueles que justificaram, destacamos as seguintes respostas ${ }^{1}$ :

Sim, através das aulas pude entender melhor os objetivos de ter uma alfabetização geográfica, durante as aulas pude me localizar, reconhecer o meio em que vivo e suas características, os processos que o fizeram como é e isso contribui para minha formação e para meu trabalho no futuro com uma leitura de mundo diferente (R.M.M.).

\footnotetext{
1 Como forma de preservar a identidade das estudantes, optamos por usar apenas as iniciais de seus nomes completo.
} 
Sim, proporcionou um entendimento melhor sobre a realidade, como um meio de interpretação de mundo, uma disciplina de grande importância para a formação de um sujeito que busca transformação (R.C.R).

Nota-se que algumas respostas indicam uma compreensão acerca do que seja a alfabetização geográfica e um auto-reconhecimento do processo desenvolvido na disciplina. Mesmo diante dos limites e desafios, percebemos que dependendo da forma como a disciplina é organizada e ministrada, ela pode, dentro de certos limites, promover a mediação para a leitura do espaço e, assim, vislumbrar um trabalho docente exitoso no futuro.

Straforini (2004) indica que

A possibilidade de fazer do ensino de Geografia nos anos iniciais como um caminho para compreender a realidade em que se vive, é bastante concreta[...]. Também neste nível de ensino é possível ensinar Geografia e torná-la interessante, despertando nas crianças um interesse maior de procurar entender o mundo em que vivemos (STRAFORINI, 2004, p.18).

Entretanto, o fato de $27 \%$ não ter justificado a resposta, pode sugerir (apenas) a não compreensão integral do processo de alfabetização geográfica, visto que a apreensão envolve processos de sínteses via escrita e outras formas de comunicação.

Para que o ensino de Geografia nos anos iniciais do ensino fundamental ocorra, conforme Straforini (2004) sugere, é imprescindível que os professores dominem os instrumentos teórico conceituais. Nesse sentido, Fantin, Tauschek e Neves questionam: “como posso querer 'ensinar' uma disciplina se eu não compreendo o seu papel no currículo, seus objetivos políticos e pedagógicos e a sua importância na formação dos alunos/sujeitos?" (FANTIN; TAUSCHEK; NEVES, 2013, p. 19-20). Reforçamos, com a seguinte questão: como posso querer mediar o processo de alfabetização geográfica se eu não fui alfabetizado geograficamente?

Segundo Dermeval Saviani

[...] é justamente porque a competência técnica é política que se produziu a incompetência técnica dos professores, impedindo-os de transmitir o saber escolar às camadas dominadas quando estas, reivindicando o acesso a esse saber por percebê-lo, ainda que de modo difuso e contraditório, como algo útil à "superação de suas dificuldades objetivas de vida", forçam e conseguem, embora parcialmente e de modo precário, ingressar nas escolas. (SAVIANI, 2008a, p. 30).

Observa-se a dimensão estratégica e política da produção de incompetência técnica dos professores mediante ao esvaziamento e aligeiramento das formações iniciais (SAVIANI, 
2009), bem como no trato mercantil da educação que tem avançado a passos largos nas últimas décadas no Brasil e no mundo. Em consonância, ao considerar o perfil dos egressos em licenciatura em Pedagogia (FERREIRA; TARTAGLIA, 2020), urge uma importante contradição: o mesmo grupo que tem um ensino básico comprometido é aquele que, majoritariamente, tem acessado as licenciaturas de Pedagogia aligeiradas e, muitas vezes, esvaziadas de conteúdo. É flagrante a estratégia de classe que os dominadores operam para impedir as classes subalternas de acessarem os conhecimentos sistematizados pela mediação da incompetência técnica dos professores, dentre outros fatores (SAVIANI, 2008a).

A segunda questão aborda as perspectivas de trabalho futuro com o ensino de Geografia. Então perguntamos: "Você avalia que o seu aproveitamento na disciplina seja suficiente para iniciar a sua práxis docente nos anos iniciais do ensino fundamental, no que diz respeito ao ensino de Geografia? Justifique”. Nessa questão, observamos dois agrupamentos de respostas. No primeiro, destacamos as respostas que indicam a insuficiência do aproveitamento na disciplina. Nesse caso, $41 \%$ dos estudantes disseram que o aproveitamento na disciplina não foi suficiente. Dentre estes, destacamos:

\footnotetext{
Não, apesar de ter sido muito proveitoso e ter aprendido bastante, acredito ainda ser insuficiente. Ainda tenho muitas dificuldades, talvez pelo fato de ter tido um ensino geográfico que hoje considero ruim no fundamental e ensino médio (S.M.A).
}

Não. Preciso adentrar mais ao conteúdo, em busca de conhecimento e a prática. No entanto me deu respaldo para um olhar em buscas de novas possibilidades (V.S.).

Acredito que seja um norteador. Me deu base mais segura para tratar o currículo. Mas sempre podemos nos aprofundar mais (R.M.M.).

Notamos a compreensão dos limites e a insuficiência dentro de uma disciplina de carga horária aligeirada e, ao considerarmos o perfil dos estudantes do curso, observamos como a falta de um ensino básico bem estruturado e de qualidade impedem um aproveitamento maior da disciplina. Além disso, percebemos que algumas respostas indicam o entendimento de que a disciplina serviu como uma iniciação para um aprofundamento posterior. É fato que as formações continuadas devem ser ofertadas para todos os professores e professoras. Todavia, será que são prioridades no que diz respeito ao ensino de Geografia? Sobre a formação docente, Castellar questiona:

Como fazer com que o professor decida os conteúdos, perceba os conceitos que devem ser articulados nos conteúdos, saiba lidar com a faixa etária, atue no sentido de efetuar uma aprendizagem significativa, se encontramos, hoje em dia, principalmente nas escolas da rede pública, professores que não são formados nas disciplinas em que 
lecionam[...]. O processo ensino-aprendizagem já começa debilitado, pois, se o professor não tem clareza sobre seu papel, em uma concepção em que a construção de conceitos e a aprendizagem significativa são determinantes, como fazê-lo romper com a prática tradicional? São poucos os investimentos institucionais em formação de professor, a qual deveria ser continuada (CASTELLAR, 1999, p. 54).

Não temos a pretensão de responder estas questões neste trabalho, mas observamos que o interesse maior nas formações continuadas para o público da Pedagogia está mais vinculado a outras temáticas. Segundo o website "Educa Mais Brasil”, as pós-graduações mais procuradas no nosso país pelos estudantes de Pedagogia são: Psicopedagogia, Psicopedagogia Clínica e Institucional; Educação Especial e Inclusiva; Neuropsicopedagogia; Pedagogia Social; Psicomotricidade; dentre outras. Ou seja, na maioria dos casos, os estudantes que não tiveram uma boa formação inicial no que tange à Geografia, dificilmente buscarão uma formação continuada específica à Geografia. Entretanto, acreditamos que cabe ao Estado ofertar tais formações aos docentes dentro do âmbito de suas secretarias de educação e não mediante ao financiamento de instituições privadas, como vem ocorrendo no Brasil há alguns anos (FERREIRA; TARTAGLIA, 2020).

Referenciando Castellar (2005), Silva e Silva (2018), analisando o resultado de uma pesquisa com professores dos anos iniciais do ensino fundamental, constatam as dificuldades no processo formativo de tais profissionais, sobretudo quanto à compreensão dos conceitos da Geografia. Assim, destacam a

[...] importância da formação regular e continuada na aquisição dos saberes específicos e para a constante reflexão sobre prática docente nos anos iniciais. Para atender a esta demanda, é preciso oferecer cursos, de média ou longa duração, que tratem de conteúdos específicos associados à prática pedagógica. Deste modo, a Escola e a Secretaria de Educação precisam incentivar seus professores a participar e a construir uma formação continuada que possibilite aumentar o conhecimento em relação a Geografia Escolar e para que possam aprimorar as atividades pedagógicas de maneira mais atrativa e condizente com a realidade dos alunos deste nível de ensino (SILVA; SILVA, 2018, p. 257).

No outro grupo estão as respostas que indicam relativa suficiência do aproveitamento para o início da práxis educativa. Assim, as estudantes indicam:

Sim, pois para lecionar é necessário entender primeiramente qual é a importância, os objetivos e a função da Geografia, e isso ficou bem claro na teoria (N.B.O.).

Eu tive um bom aproveitamento nessa disciplina, pois analisando o ensino que tive no fundamental pude perceber que a Geografia vai além de mapas e conceitos básicos, possibilitando uma nova compreensão sobre esse ensino (R.C.R.). 
É importante que haja esta compreensão dos objetivos, da função e da importância da Geografia. Porém, é suficiente ou é apenas o ponto de partida? A suficiência para iniciar não deveria estar associada ao domínio das categorias e conceitos para a efetivação da alfabetização geográfica?

Saviani (2001), ao conceber as bases teóricas para uma educação transformadora e discorrer sobre os conteúdos sistematizados, aponta que é fundamental garantir aos dominados aquilo que os dominadores detêm para a busca da superação da condição de dominação. Assim, para uma educação ser, de fato, transformadora é imprescindível que os docentes dominem os conceitos e categorias para conduzirem processos educativos que possibilitem a alfabetização geográfica.

Diante dos diálogos com autores, das vivências e experiências ministrando a disciplina de "Fundamentos Teóricos e Metodológicos do Ensino de Geografia" podemos inferir que uma única disciplina durante a licenciatura em Pedagogia não é absolutamente suficiente para mediar o processo de alfabetização geográfica de todos os estudantes. Assim, muitos pedagogos e pedagogas regentes não conseguirão atuar de forma a mediar a o desenvolvimento do raciocínio e do olhar geográfico junto aos seus alunos.

Contudo, entendemos que a escolha da perspectiva teórico-metodológica, o planejamento e a organização do trabalho dos professores que lecionam as disciplinas de ensino de Geografia nos cursos de Pedagogia podem potencializar o processo de alfabetização geográfica dos licenciandos. Em suma, é possível que ocorra a construção do olhar geográfico e a apropriação dos instrumentos teóricos basilares para ensinar a Geografia, após a formação no curso de Pedagogia. Porém, dentro de limites intrínsecos ao histórico e perfil dos estudantes, ao planejamento e abordagem no desenvolvimento da disciplina, bem como à carga horária destinada à Geografia. Cabe reforçar que o foco integral nas metodologias de ensino da Geografia, deixando de lado os aspectos teóricos e conceituais, são impeditivos para um processo formativo mais amplo e profundo.

Depreende-se, então, a importância da ampliação da carga horária destinada ao ensino de Geografia na formação inicial, como a construção sistemática de formação de professores inicial e continuadas que contemplem o conhecimento geográfico articulando os aspectos teóricos às metodologias de ensino. 
Concluímos, destacando elementos desta perspectiva pedagógica, a pedagogia histórico-crítica. Especificamente sobre a formação docente, Saviani (2008a) contribui grandemente ao indicar e discutir o conceito de competência técnica e compromisso éticopolítico na práxis docente. O autor afirma que

[...] pela mediação $d a$ competência técnica que se chega ao compromisso político efetivo, concreto, prático, real. $\mathrm{Na}$ verdade, [...] a competência técnica significa o conhecimento, o domínio das formas adequadas de agir: é, pois, o saber-fazer. Nesse sentido, ao nos defrontarmos com as camadas trabalhadoras nas escolas, não parece razoável supor que seria possível assumirmos o compromisso político que temos para com elas sem sermos competentes na nossa prática educativa. O compromisso político assumido apenas no nível do discurso pode dispensar a competência técnica. Se se trata, porém, de assumi-lo na prática, então não é possível prescindir dela. Sua ausência não apenas neutraliza o compromisso político mas também o converte no seu contrário [...] (SAVIANI, 2008a, p. 36).

Evidencia-se, em Saviani (2008a), que o processo de formação docente é fundamental na busca pela transformação social, articulando firmemente à competência técnica, isto é, todos os saberes indispensáveis ao trabalho docente - saber atitudinal; saber crítico-contextual; saberes específicos; saber pedagógico, e o saber didático contextual (cf. SAVIANI, 1996) - ao compromisso ético-político. Pois ao apropriar-se dos instrumentos técnicos e teóricos o docente encontrará melhores condições para mediar potentemente o processo dialético de desvelamento da realidade junto aos educandos.

Salientamos que a pedagogia histórico-crítica expressa uma práxis pedagógica em um horizonte de transformação social, pois se coloca em uma posição de luta pela apropriação dos conteúdos historicamente construídos pelo conjunto da humanidade. Todavia, estes saberes sistematizados foram também historicamente segregados a determinados grupos e classe. Nesse caso, a educação escolar ganha centralidade na transmissão destes conteúdos eruditos ou clássicos (SAVIANI, 2008a), principalmente para os estudantes da escola pública. Percebe-se, então, como a formação docente promotora da competência técnica é importante, pois o trabalho educativo é fundamental no processo de apropriação dos conhecimentos sistematizados.

É sob essa dimensão que o ensino de Geografia se insere, tornando flagrante um ponto de tensão: se por um lado observamos com clareza os limites e desafios pertinentes a formação docente inicial e continuada dos professores que trabalharão com o ensino de Geografia nos 
anos iniciais do ensino fundamental, por outro, percebemos a urgência em uma práxis docente nesta perspectiva transformadora.

\section{CONSIDERAÇÕES FINAIS}

Este trabalho foi instigado pelas experiências vivenciadas no magistério superior no curso de Pedagogia entre os anos de 2018 a 2020. As possibilidades, os desafios e os limites do trabalho docente diante das grandes contradições da sociedade hodierna e, em especial, da educação, suscitaram demandas de leituras e reflexões sobre a disciplina de "Fundamentos Teóricos e Metodológicos do Ensino de Geografia". Ao percebermos as dificuldades inerentes a múltiplos fatores sociais, políticos e econômicos, fizemos o esforço reflexivo acerca da estrutura e organização da disciplina em destaque.

Percebemos que o trabalho docente na disciplina referida, dentro do âmbito da licenciatura em Pedagogia, pode ser potencializado pelo planejamento docente articulado com bases teórico-metodológicas e conceituais coerentes. Nesse caso, a articulação entre a pedagogia histórico-crítica e a Geografia Crítica enriquecem o processo de ensino-aprendizado mediando, dentro de certos limites, o desenvolvimento de um olhar geográfico e, portanto, da alfabetização geográfica de alguns discentes. Os limites estão relacionados à diversos fatores, porém, destacam-se aqueles vinculados ao perfil socioeconômico dos estudantes, a dificuldade de acesso aos saberes sistematizados durante o ensino básico, o aligeiramento das formações iniciais e as contradições das formações continuadas ofertadas pelas secretarias de educação ou vendidas por empresas privadas de educação.

As questões levantadas nos levaram a deduzir que uma única disciplina durante a licenciatura em Pedagogia não é categoricamente suficiente para subsidiar a atuação dos estudantes de Pedagogia como professores no ensino de Geografia. Dessa maneira, muitos futuros professores dos anos iniciais do ensino fundamental não terão fundamentação para atuarem como mediadores no desenvolvimento do raciocínio e do olhar geográfico em conjunto com seus alunos.

Essas deduções necessitam de um esforço mais amplo e profundo de estudo empírico e análise, mas, a priori, demonstram que devemos tratar esta questão com uma atenção especial, pois o ensino de Geografia dá contribuições para possibilidades da construção de um outro mundo, no horizonte de transformação da realidade, e de uma outra produção de existência, 
alternativa ao modelo societário atual centrado na mercadoria (STRAFORINI, 2004). Nesse sentido, o processo de alfabetização geográfica ganha contornos de elevada relevância, visto que é a partir dele que se constrói um olhar instrumentalizado para o espaço, possibilitando a superação da percepção reificada que é incutida nos sujeitos dentro do ethos societário capitalista. Por isso, apostamos e defendemos a formação docente inicial e continuada de qualidade, e entendemos como importante repensar a estrutura curricular das graduações de Pedagogia. Além disso, concordamos com Silva e Silva (2018), quando apontam a necessidade de articular parcerias entre o curso de Geografia e o curso de Pedagogia nas faculdades e universidades.

Entendemos que os limites são muitos, mas não são intransponíveis. Os desafios são grandes, mas não devem superar a esperança crítica de todos aqueles que acreditam no caráter transformador da educação. Por fim, o grande geógrafo Milton Santos contribui ao afirmar que "Uma ciência digna desse nome deve preocupar-se com o futuro" (SANTOS, 2008, p.261). Nesse compasso, entendemos que a construção de um novo futuro só pode ocorrer a partir da aproximação da compreensão da realidade concreta, constituída social e historicamente. No caso do conhecimento geográfico, o olhar instrumentalizado para o espaço.

Destarte, um olhar mediado para o espaço geográfico se faz necessário. Um olhar que busca descortinar a realidade para possibilitar a apreensão aproximada do real concreto. Somente a partir daí é possível intervir/transformar a realidade de forma potente e coerente (dentro das condições objetivas e determinadas de cada momento histórico). Enquanto a visão de mundo for míope, nossas ações serão incompatíveis com as necessidades suscitadas por ela.

\section{REFERÊNCIAS}

BRAGA, M. C. O ensino de Geografia nas séries iniciais do ensino fundamental: uma análise dos descompassos entre a formação docente e as orientações das políticas públicas. Revista Terra Livre, São Paulo, v.1, n. 28, 2007.

BRASIL. Lei de Diretrizes e Bases da Educação Nacional, LDB. 9394/1996.

CALLAI, H. C. O conhecimento geográfico e a formação do professor de Geografia. Revista Geográfica da América Central. Heredia, Costa Rica. Número Especial EGAL, p. 1-20, 2011.

CAMACHO. R. S. O Ensino de Geografia nos Anos Iniciais do Ensino Fundamental: um Caminho para compreender a realidade em que se vive. R. Ens. Geogr. Uberlândia, vol.2, n. 3, p. 3-35, jul./dez. 2011. 
CASTELLAR, S. M. V. A formação de professores e o ensino de Geografia. Revista Terra Livre: As transformações no mundo da Educação, 1999, v. 14, p. 48-57.

CASTELLAR, S. M. V. Educação geográfica: teorias e práticas docentes. São Paulo: Contexto, 2005.

CASTROGIOVANNI, A. C. GOULART, Lígia Beatriz. Uma contribuição à reflexão do Ensino de Geografia: a noção de espacialidade e o estudo da natureza. Revista Terra Livre. São Paulo, n. 7, s/p. 1990.

CAVALCANTI, L. de S. Geografia, escola e construção do conhecimento. Campinas: Papiro, 1998.

CAVALCANTI, L. de S. A Geografia e a realidade escolar contemporânea: avanços, caminhos e alternativas. In: I Seminário Nacional: currículo em movimento - Perspectivas atuais. Anais I Seminário Nacional: currículo em movimento. Belo Horizonte, 2010. P. 1-16. Disponível em: http://portal.mec.gov.br/docman/dezembro-2010-pdf/7167-3-3-geografiarealidade-escolar-lana-souza/file Acesso em: 20 Out. 2020.

COUTO, M. A. C. Ensino de Geografia: uma abordagem Histórico-Crítica. Tamoios. São Gonçalo, Ano 5, n.2, p. 2-15, 2009.

FANTIN; TAUSCHEK; NEVES. Metodologia de Ensino de Geografia. São Paulo: Editora Intersaberes, 2013.

FERREIRA, E. B.; TARTAGLIA, L. M.. Perfil e formação dos estudantes de Pedagogia no Brasil: um relato de experiência desde as IES privadas. In: LACERDA, G.H.F.; FROIS, I.D.O.; TARTAGLIA, L.M.; RAULINO, R. (Orgs). Universidade em debate: políticas, gestão e prática docente. Porto Seguro: Editora Oyá, 2020. P. 17-38.

FOSTER, J. B. A Ecologia de Marx: materialismo e natureza. 4. ed. Rio de Janeiro: Civilização Brasileira. 2014.

GIROTTO, E. D. ENSINO DE GEOGRAFIA E RACIOCÍNIO GEOGRÁFICO: as contribuições de Pistrak para a superação, Revista Brasileira de Educação, v.5, n.9, p.71-86, 2015.

GOLÇALVES, T. R. de P. da S.; PINTO, V. P. dos S. Alfabetização geográfica na educação brasileira. Revista de Estudo e Pesquisa em Educação. Juiz de Fora, vol. 17, n. 2, p. 177187, jul./dez. 2015.

HARVEY, D. A produção capitalista do espaço. São Paulo: Annablume, 2005.

KOSIK, K. Dialética do concreto. Rio de Janeiro: Paz e Terra, 2010.

LEFEBVRE, H. A produção do espaço. Trad. Doralice Barros Pereira e Sérgio Martins. Primeira versão: início - fev.2006.

LACOSTE, Y. A Geografia - Isso Serve, Em Primeiro Lugar, Para Fazer a Guerra. Papirus Ed.: São Paulo-SP, 1988.

MARX, K. Manuscritos econômicos- filosóficos. São Paulo. Boitempo, 2004.

MOREIRA, R. O que é Geografia. São Paulo: Brasiliense, 1998. 
RAMOS, A. W. Espaço-tempo na cidade de São Paulo: historicidade e espacialidade do "bairro" da água branca. Revista do Departamento de Geografia - Departamento de Geografia da FFLCHUSP, São Paulo, n. 1, p. 65-75, 1982

SANTOS, M. Técnica, espaço, tempo: globalização e meio técnico-científico-informacional. São Paulo. HUCITEC, 1994.

SANTOS, M. Metamorfoses do Espaço Habitado. 4. ed. São Paulo: Ed. Hucitec, 1996.

SANTOS, M. A natureza do espaço. Técnica e tempo. Razão e emoção. São Paulo. HUCITEC, 2002.

SANTOS, M. Por uma Geografia Nova. São Paulo: Edusp, 2008.

SAVIANI, D. Os saberes implicados na formação do educador. In: BICUDO, M. A.; SILVA JUNIOR, C. A. (Org.). Formação do educador: dever do Estado, tarefa da Universidade. São Paulo: Unesp, 1996.

SAVIANI, D. Escola e Democracia. 34. ed. rev. Campinas, Autores Associados, 2001.

SAVIANI, D. Pedagogia Histórico-Crítica: primeiras aproximações. 10. ed. Campinas: Autores Associados, 2008a.

SAVIANI, D. A nova lei da educação (LDB): trajetória, limites e perspectivas. 11. ed. Campinas: Autores Associados, 2008b.

SAVIANI, D. Formação de professores: aspectos históricos e teóricos do problema no contexto brasileiro. Rev. Bras. Educ. Rio de Janeiro, vol.14, n.40, p.143-155, 2009.

SAVIANI, D. O conceito dialético de mediação na pedagogia histórico-crítica em intermediação com a psicologia histórico-cultural. Germinal: Marxismo e Educação em Debate, Salvador, v. 7, n. 1, p. 26-43, jun. 2015.

SILVA, T. P.; SILVA, L. R. O Ensino de Geografia nos anos iniciais do fundamental: reflexões sobre formação e práticas pedagógicas. Revista Brasileira de Educação em Geografia. Campinas, vol. 8, n.15, p. 242-265, jan./jun., 2018.

STRAFORINI, R. Ensinar geografia: o desafio da totalidade-mundo nas séries iniciais. 2. ed. São Paulo: Annablume, 2004.

TEIXEIRA, W.; FAIRCHILD, T. R.; TOLEDO, M. C. M.; TAIOLI, F. Decifrando a Terra. $2^{a}$ edição, São Paulo, SP; Companhia Editora Nacional, 623p. 2007.

TEIXEIRA, L. A. As contribuições da Pedagogia Histórico-Crítica para o ensino de geografia. Germinal: Marxismo e Educação em debate. Salvador, v. 7, n. 1, p. 189-199, jun. 2015 .

VESENTINI, J. W. Geografia Crítica e Ensino. In: OLIVEIRA, Ariovaldo Umbelino. (org). Para onde vai o ensino de geografia. São Paulo: Contexto, 2012. p. 30-38. 